\title{
Update on treatment of polymyalgia rheumatica
}

\section{Camellino ${ }^{1,2}$, C. Dejaco ${ }^{3,4}$}

${ }^{1}$ Division of Rheumatology, Locomotor Apparatus Department, La Colletta Hospital, ASL3 Genovese, Arenzano (GE), Italy; ${ }^{2}$ Autoimmunology Lab, Department of Internal Medicine, University of Genova, Italy; ${ }^{3}$ Service of Rheumatology, ASL dell'Alto Adige, Hospital of Brunico, Brunico (BZ), Italy;

${ }^{4}$ Department of Rheumatology, University of Medicine of Graz, Graz, Austria

\section{SUMMARY}

Polymyalgia rheumatica (PMR) is the second most common inflammatory rheumatic disease in the elderly after rheumatoid arthritis. It is clinically characterised by pain and stiffness in the neck, proximal shoulder and hip girdle. Glucocorticoids (GCs) are the cornerstone of PMR treatment, but they are associated with potentially severe side effects.

Among GC-sparing agents, methotrexate revealed a modest benefit in clinical trials, and recently, there have been promising reports from tocilizumab.

In this review, we summarize the available evidence on the treatment of PMR and the possible role in the future of other agents under investigation.

Key words: Polymyalgia rheumatica; large vessel vasculitis; glucocorticoids; disease modifying anti-rheumatic drugs; biologics.

Reumatismo, 2018; 70 (1): 59-66

\section{INTRODUCTION}

Dolymyalgia rheumatica (PMR) is the second most common inflammatory rheumatic disease in the elderly after rheumatoid arthritis (RA) $(1,2)$. It is clinically characterised by pain and stiffness in the neck, proximal shoulder and hip girdle. Peripheral manifestations such as tenosynovitis of the hands or knee synovitis may occur in up to $45 \%$ of patients, while $20 \%$ of cases clinically overlap with giant cell arteritis (GCA) $(3,4)$.

Glucocorticoids are still the treatment of choice for PMR. Treatment duration usually exceeds 12 months and may be significantly longer in cases with relapsing disease (5). Adverse events are frequent, particularly in patients with insufficient response to GCs or recurrent disease flares (6).

Among GC sparing agents, methotrexate (MTX) revealed a modest benefit in clinical trials, and recently, there have been promising reports for tocilizumab for treatment of this disease.

In the present article, we summarize state- of-the-art therapy in PMR, and discuss future therapeutic developments in the field.

\section{GLUCOCORTICOID THERAPY}

\section{Oral glucocorticoids}

According to the 2015 European League Against Rheumatism-American College of Rheumatology (EULAR-ACR) recommendations for the management of PMR, treatment of PMR patients should be individualized using the minimum effective GC dose and treatment duration (5). This recommendation is mainly based on consensus given that evidence from clinical trials on initial GC dose, subsequent tapering regimen as well as total duration of therapy is scarce (7). It is recommended to start oral GCs at a daily dose between 12.5 and $25 \mathrm{mg}$ prednisone equivalent (Table I).

Physicians treating PMR should take into account the presence of risk factors for relapses/prolonged treatment [such as female sex, erythrocyte sedimentation rate (ESR) $>40 \mathrm{~mm} / \mathrm{h}$ and peripheral arthritis] and factors increasing the risk for $\mathrm{GC}$ related
Corresponding author:

Dario Camellino

S.C. Reumatologia, Ospedale "La Colletta",

Dipartimento Apparato

Locomotore (Di.A.L.), ASL3 Genovese

Via Del Giappone, 3

16011 Arenzano (GE), Italy

E-mail: dario.camel@gmail.com 
adverse events or comorbidities that might be exaggerated by GC therapy (e.g. pre-existing osteoporosis, diabetes, hypertension etc.). Patients with risk factors for relapses/ prolonged therapy may be treated with a higher initial GC dose within the specified range, whereas in case of an increased risk for adverse events a lower dose should be considered.

A single randomized controlled trial (RCT) has been published testing different initial GC doses for PMR (8). Thirty-nine patients were randomly assigned either to 20 $\mathrm{mg}$ or to $10 \mathrm{mg}$ prednisone daily. A higher relapse rate after 2 months was observed in the low-dose group (65\% vs $11 \%$ ), while the adverse events were more common in patients treated with the higher dose $(26 \%$ vs 0\%) (9). Several retrospective studies analysed the outcome of patients treated with different initial GC doses, reporting divergent results (10-13). One of these studies $(n=132)$ observed a higher prevalence of adverse events ( $21 \%$ vs $3 \%)$ in patients treated with an initial dose of $>15$ mg prednisone per day compared to those receiving a lower dose (10).

Initial GC doses higher than $25 \mathrm{mg} /$ day are discouraged because of a high risk of adverse events and because there is no evidence that such doses are more effective than lower doses $(5,7)$. One retrospective study even observed that higher initial CS doses were a predictor of future relapses (14). Another study suggested that the initial prednisone dose should be adjusted to body weight (adjusting the prednisone dose to $\sim 0.2 \mathrm{mg} / \mathrm{kg} / \mathrm{day}$ ) given that in that study, body weight was the most important predictor of a good response to initial treatment (15).

After initial treatment and provided a clinical response has been achieved, tapering of GCs should be gradual with a target prednisone dose of $10 \mathrm{mg}$ per day after 4-8 weeks. One single retrospective study $(n=364)$ investigated the effect of slow $v s$. fast GC tapering on the relapse rate, using

Table I - Therapy of polymyalgia rheumatica according to the 2015 EULAR-ACR recommendation (5).

\begin{tabular}{|c|c|c|}
\hline Event & Dose & Specifications \\
\hline \multicolumn{3}{|l|}{ Oral prednisone } \\
\hline Initial treatment & $12.5-25 \mathrm{mg} /$ day & $\begin{array}{l}\text { Higher dose if risk factors for relapse/prolonged therapy } \\
\text { (female sex, high ESR, peripheral arthritis) } \\
\text { Lower dose if risk factors for adverse events } \\
\text { (comorbidities, female sex, comedication) }\end{array}$ \\
\hline At $4-8$ weeks & Target dose $10 \mathrm{mg} /$ day & $\begin{array}{l}\text { Assuming a response to GC treatment } \\
\text { (defined improvement of PMR symptoms by } 70 \% \text { on a VAS) }\end{array}$ \\
\hline$>4-8$ weeks & $\begin{array}{l}\text { Taper by } 1 \mathrm{mg} / \mathrm{month} \text { until } \\
\text { discontinuation }\end{array}$ & $\begin{array}{l}\text { In case } 1 \mathrm{mg} \text { tablets are not available or } 1 \mathrm{mg} \text { reductions are not feasible, } \\
\text { similar dose reduction strategies might be applied }\end{array}$ \\
\hline Relapse & Increase to pre-relapse dose & $\begin{array}{l}\text { Until remission is re-achieved, then taper to dose where relapse } \\
\text { occurred within 4-8 weeks }\end{array}$ \\
\hline \multicolumn{3}{|c|}{ Intramuscular methlyprednisone } \\
\hline Initial treatment & 120 mg every 3 weeks & $\begin{array}{l}\text { Possible alternative to oral prednisone if available and a lower cumulative } \\
\text { GC dose is desired }\end{array}$ \\
\hline $12-48$ weeks & $\begin{array}{l}100 \mathrm{mg} \text { every month, dose reduction by } \\
20 \mathrm{mg} \text { every } 12 \text { weeks }\end{array}$ & \\
\hline$\geq 48$ weeks & $\begin{array}{l}40 \text { mg every month, dose reduction } \\
\text { by } 20 \text { mg every } 16 \text { weeks until } \\
\text { discontinuation }\end{array}$ & \\
\hline \multicolumn{3}{|l|}{ Methotrexate } \\
\hline Initial therapy & $7.5-10 \mathrm{mg} /$ week & $\begin{array}{l}\text { Concomitantly to oral prednisone in case of risk factors for relapse/ } \\
\text { prolonged therapy or adverse events }\end{array}$ \\
\hline Follow-up & $7.5-10 \mathrm{mg} /$ week & $\begin{array}{l}\text { In case of relapse, insufficient response to prednisone or prednisone } \\
\text { related adverse events }\end{array}$ \\
\hline
\end{tabular}


a statistically modelled tapering constant. A faster reduction of the GC dose was associated with an up to 5-fold risk of relapse compared to slower tapering (14).

PMR has often been defined by a rapid response to GC treatment $(16,17)$. Improvement of symptoms, however, might also more be gradual, as observed in the study aimed at developing the provisional 2012 ACR-EULAR classification criteria. In that study, only $73 \%$ of patients achieved a response by week 4 as defined by an improvement of PMR symptoms by $70 \%$ (measured on a visual analogue scale) (18). A complete response, defined as all 3 of the following:

1. $\geq 70 \%$ improvement in PMR VAS;

$2 . \geq 70 \%$ reduction in duration of morning stiffness;

3. normal CRP and/or ESR, was observed in only $53 \%$ of patients (18).

The 2015 EULAR-ACR recommendations for PMR therefore stipulated that the assessment of treatment response should be after 2-4 weeks. Patients achieving remission might then be tapered down by $1 \mathrm{mg}$ prednisone every 4 weeks until discontinuation. The EULAR-ACR task force recognized that $1 \mathrm{mg}$ tablets are not available in each country; hence, alternative tapering regimens might be applied as long as dose reduction is gradual. This tapering regime implies a minimum duration of therapy of 12 months; however, treatment might be much longer, even life-long, if a patient has recurrent relapses. Although this topic has not been addressed in the literature, everyday clinical experience suggests that PMR patients are often treated in primary care with higher GC doses and for shorter periods of time than actually recommended, despite the fact that both these approaches have been related to a higher relapse rate (14).

For treatment of a relapse, it is recommended that GCs be increased to the previously effective dose, with subsequent dose reduction within 4-8 weeks to the dose at which the relapse occurred (5). Specialist referral should be considered at each relapse or in cases with an inadequate response to GCs. Oral prednisone should be administered as a single morning dose. In situations where prominent night pain occurs, particularly if the prednisone dose has been tapered below $5 \mathrm{mg}$ /day, a small evening dose might be considered.

\section{Glucocorticoid related adverse events}

GC adverse events are common, occurring in up to $65 \%$ of patients $(19,20)$. The most common adverse events include weight gain, oedema, mental disturbances and gastrointestinal side effects. Other adverse events particularly feared by patients are osteoporosis, diabetes and cardiovascular events (21).

Patients undergoing GC therapy should be subject to regular monitoring for adverse events as specified by an EULAR task force (22). This includes regular measurement of blood pressure, body weight, fasting glucose and assessment for osteoporosis (following national guidelines). At baseline, patients should be further investigated for the presence of ankle oedema, (risk factors for) cardiovascular disease, peptic ulcer disease, and risk factors for glaucoma (such as positive family history, high myopia, diabetes). In case patients are at an increased risk for glaucoma, an ophthalmologic examination should be scheduled.

\section{Alternative glucocorticoid preparations}

EULAR-ACR recommendations stipulated that intramuscular (i.m.) methylprednisolone (MP) might be used as an alternative to oral GCs in individual PMR patients, particularly in those where a low cumulative GC dose is desired (5). I.m. MP has been tested in a 96-week double-blinded RCT. Patients $(n=60)$ received either MP (120 mg i.m. every 3 weeks) or oral prednisone (starting dose $15 \mathrm{mg}$ ). The proportion of patients in remission was comparable in both groups; however, the cumulative GC dose $(2.0 \mathrm{~g} v s 3.5 \mathrm{~g})$ as well as weight gain $(0.8 \mathrm{~kg}$ vs $3.4 \mathrm{~kg})$ were lower in the i.m. MP group (23). I.m. MP is not available in every country.

Another GC preparation that might be considered for PMR treatment is modified-release prednisone (MR prednisone). Taken at bedtime, prednisone is released at $\sim 2$ a.m. thus enabling optimal chrono- 
therapy. MR prednisone was successfully tested in RA $(24,25)$, whereas for PMR, the only RCT was terminated early because of insufficient recruitment. Instead of 400 patients planned, only 62 patients were included. The trial failed marginally its primary endpoint, which was non-inferiority over conventional prednisone to achieve a complete response at week 4 (54\% in MR vs $41 \%$ in conventional prednisone group). A complete response was defined as $\geq 70 \%$ improvement from baseline in PMR visual analogue scale, duration of morning stiffness and C-reactive protein. In sub-analyses, there was a trend for superiority of MR prednisone over conventional treatment (26).

\section{GLUCOCORTICOID SPARING AGENTS}

\section{Conventional synthetic DMARDs}

In order to reduce the occurrence of GCrelated side effects, which cause a significant burden to the population of older patients, much effort has been spent on investigating the value of disease-modifying anti-rheumatic drugs (DMARDs). MTX has been studied in both RCTs and retrospective studies $(11,27-29)$. Some studies revealed higher remission rates, more frequent discontinuation of GCs and lower cumulative GC doses $(28,29)$, whereas others reported conflicting results with no clear benefit of MTX on remission (27), or a similar rate of GC-related adverse events in patients taking MTX+GCs $v s$. those with GCs alone (30). In particular, the trial by Van der Veen et al. (27) showed no differences among patients taking GC only and those taking $\mathrm{GC}+\mathrm{MTX}$ regarding the time to achieve remission, duration of remission, number of relapses and cumulative prednisone dose. This study was doubleblind and randomized but enrolled a small number of patients, of whom six also had GCA. Besides, this trial was limited by attrition since $48 \%$ of patients dropped out from the study. The trial by Ferraccioli et al. (28) showed a significant effect of MTX in both achieving remission and sparing GCs, with a documented protective effect of MTX on bone resulting from the lower cumulative GC dose. The trial by Caporali et al. (29) reported a 34\% lower probability of taking prednisone at week 76 in the MTX compared to the control group. The median cumulative prednisone dose in patients treated with MTX was $2.1 \mathrm{~g}$ vs 3.0 $\mathrm{g}$ for patients taking GCs only. The precise role of MTX in the treatment of PMR has been long debated (31): many data support its use, however the magnitude of the real clinical benefit has been questioned, and indisputable demonstration of a reduction of GC-related side effects in patients taking MTX is not available. The modest clinical effect of MTX observed in clinical trials might also be related to the low doses (7.5-10 mg/week) used. In RA, MTX is usually applied at doses of $15-25$ $\mathrm{mg} /$ week. Moreover, except for the trial by Ferraccioli et al., oral formulations of MTX were employed, with possible lower efficacy compared to the parental administration (32).

The 2015 EULAR-ACR recommendations for the management of PMR (5) suggest the use of MTX in patients at high risk for relapses and/or GC-related side effects. During follow-up, MTX might be used in cases with relapsing disease. It is important to note that MTX is currently not approved for treatment of PMR.

Data on other DMARDs are scarce. Hydroxychloroquine has been evaluated in a retrospective study with no evidence of benefit compared to GCs alone (11). The successful use of leflunomide has been reported in case series of patients with GC resistant PMR and GCA $(33,34)$. The potential efficacy of azathioprine as a steroid sparing agent has been tested in a doubleblind placebo-controlled trial of PMR and GCA patients (with pooled analysis of both groups). Although the authors noted that patients treated with azathioprine needed fewer GCs, the frequency of side effects discouraged its use and therefore this drug is currently not considered as a therapeutic option for PMR.

RCTs on conventional DMARDs are urgently warranted to study better the efficacy and safety of these drugs in PMR. 


\section{Biologic DMARDs}

Anecdotal cases of clinical and laboratory improvement of patients with PMR treated with TNF $\alpha$ inhibitors have been reported, especially cases with long-lasting disease; however, results from RCTs did not support these preliminary data. The use of infliximab in PMR has been studied in the pivotal RCT from Salvarani et al. (35), which showed no additional benefit of infliximab + GCs compared to GCs alone. A RCT of etanercept monotherapy versus placebo in patients with PMR revealed only a modest improvement in symptoms in the intervention group (36). Therefore, the 2015 EULAR-ACR recommendations strongly advise against the use of $\mathrm{TNF} \alpha$ blocking agents for the treatment of PMR (5). This has mainly been based on the lack of evidence for efficacy, the substantial risk of potential harm and the high costs of these treatments.

Several case series and retrospective studies have highlighted the potential efficacy of the anti-interleukin 6 receptor tocilizumab (TCZ) in PMR and GCA (37-39). The GiACTA trial (40), which tested the effect of TCZ in patients with GCA, showed impressive results regarding both remission rate and cumulative steroid dose, leading to the approval of TCZ by FDA as a breakthrough therapy for GCA. In contrast to GCA, the potential benefit of TCZ for treatment of PMR is less clear. Devauchelle-Pensec et al. studied the effect of TCZ monotherapy in an open-label, single-arm trial in 20 PMR patients (41): TCZ was administered at weeks 0,4 and 8 , and patients were subsequently treated with $0.15 \mathrm{mg} / \mathrm{kg}$ oral prednisone. All patients achieved the primary endpoint at week 12, which was low disease activity according to the PMR-activity score (PMR-AS); however, only 9/20 (45\%) revealed low disease activity at 4 weeks. As mentioned above, in the study aimed at developing the 2012 provisional classification criteria of PMR (42), a response rate of $73 \%$ at 4 weeks was achieved using $15 \mathrm{mg}$ oral prednisone. This suggests a more rapid effect of GCs compared to TCZ.

TCZ has also been used in association with GCs in a single-centre open-label study of
10 patients, of whom one withdrew due to an infusion reaction (43). Patients were treated with monthly TCZ $8 \mathrm{mg} / \mathrm{kg}$ for 12 months, and with GCs that were rapidly tapered and withdrawn by week 12. PMR patients who refused to receive the biologic treatment or who didn't meet the inclusion criteria, served as a comparator. They received GCs as current standard of care, tapered according to the physician's judgement. All 9 patients receiving TCZ (1 patient withdrew from the study due to an infusion reaction) achieved the primary endpoint of being in GC-free remission at month 6 , and maintained remission through the 15-month duration of the trial. None of the patients receiving GC-monotherapy were in steroid-free remission at 6 months, and at 12 months, a $60 \%$ relapse rate was seen in this group. The mean cumulative prednisone dose in patients receiving TCZ was $1085 \pm 301 \mathrm{mg}$. while in the comparator group it was more than doubled $(2562 \pm 1356$ $\mathrm{mg}$ ), suggesting a significant steroid-sparing effect of TCZ in patients with PMR.

Despite these promising results, TCZ cannot yet be recommended for routine treatment of isolated PMR. RCTs are awaited to study the benefits and risks of this therapy for PMR.

In a proof of concept, single-blind, 3-arm trial, 16 PMR patients were randomized (44) 1:1:1 to receive either secukinumab or canakinumab, as a single dose of $3 \mathrm{mg} / \mathrm{kg} /$ body weight, or to $20 \mathrm{mg} /$ day oral prednisone. At day 15, one patient in the GC arm, but no patient in the groups treated with biologics, had a complete response. Patients receiving GCs showed a rapid pronounced reduction of pain whereas in secukinum$\mathrm{ab}-$ and canakinumab-treated patients, only a moderate improvement was noted. Four patients in the secukinumab group switched to GCs. Subsequently, they used $40 \%$ fewer GCs per month than patients in the GC only group. Similarly, the three patients switching from canakinumab to GCs subsequently used 35\% fewer GCs. This observation suggests that secukinumab and canakinumab might have a steroid-sparing effect, even if they were unable to ameliorate PMR symptoms by day 15 . 


\section{FUTURE PERSPECTIVES}

In order to improve the benefit-risk ratio of GCs, there is ongoing research on novel GC (-like) molecules and GC preparations. A promising molecule is the dissociated agonist of the GC receptors [DAGR, also called selective GC receptor modulators (SEGRM)] (45). The idea is to influence anti-inflammatory cellular mechanisms selectively while preventing the activation of mechanisms promoting adverse effects. DAGR bind to the GC receptor inducing a cytosolic GC receptor/protein interaction which results in so-called trans-repression mediating immunosuppression. In contrast, DNA binding and trans-activation leads to adverse events, though this effect is much less with DAGRs (45). Another interesting development is liposomal GCs. With this preparation, GCs can be selectively delivered in inflamed tissues using nanometresized liposomes (46). Currently, DAGRs and liposomal GCs are tested in clinical trials in RA and subsequent studies in other indications such as PMR can be expected, if RA trials reveal positive results.

Janus-kinase inhibitors (JAK) represent an entirely new approach to the treatment of various autoimmune diseases. Tofacitinib and baricitinib are currently the best-studied JAK inhibitors, and they have recently been approved by EMA for RA. JAK inhibitors are under investigation in other diseases, such as psoriasis, inflammatory bowel diseases and systemic lupus erythematosus (47). Preclinical data showed the efficacy of tofacitinib in preventing $\mathrm{T}$ cells accumulation and interferon $-\gamma$ production in the vessel wall of temporal arteries from biopsies of GCA patients (48). Given its suppressive effect of on both the Th17 (related to IL-6 and IL-23) and Th1 (related to IL-12 and IFN- $\gamma$ ) pathways, baricitinib constitutes an appealing treatment for GCA. A phase-2 study, evaluating safety and efficacy of baricitinib in relapsing patients with GCA, is currently recruiting subjects (NCT03026504). A possible role of Janus kinase inhibition could also be hypothesised in PMR patients (49).
Another unresolved issue is the management of PMR associated with LVV. GCresistant PMR patients, who show LVGCA at re-evaluation, are usually treated as GCA with an increase of GC and/or the addition of MTX. Conversely, it remains unclear how PMR patients with subclinical LVV (found incidentally by imaging during work-up) should be treated. With the advent of new imaging techniques, such as positron emission tomography (PET) and angiography with magnetic resonance imaging (MRA), the vascular tracer accumulation has been demonstrated in about one-third of patients with apparently isolated PMR $(50,51)$.

Previous studies suggested that PMR patients without clinical signs of GCA but with a positive temporal artery biopsy are not at a higher risk of vasculitic complications such as visual loss $(27,52)$. On the other hand, the presence of occult LVV has been detected in patients with apparent GC-resistant PMR (53).

The inclusion criteria of the GiACTA trial also encompassed patients with clinically isolated PMR and imaging evidence of $L V V$, raising the question whether this particular sub-population should be considered a different phenotypic subset of GCA (54).

\section{CONCLUSIONS}

GCs are still the standard treatment of PMR. Due to the high prevalence of side effects, GC sparing agents are urgently needed. Whereas MTX demonstrated a modest benefit in RCTs, case series and first small open studies on TCZ revealed promising results. TCZ has recently been approved for GCA and future RCTs on this agent in PMR are awaited. Other unresolved issues are whether subclinical large vessel inflammation in PMR should be managed differently from isolated PMR, and whether rapid improvement of symptoms, normally seen with GC therapy, is a reliable outcome in studies on biological agents. Future research is necessary to answer these questions and to improve the management of PMR patients. 


\section{REFERENCES}

1. Lawrence RC, Felson DT, Helmick CG, et al. Estimates of the prevalence of arthritis and other rheumatic conditions in the United States. Part II. Arthritis Rheum. 2008; 58: 26-35.

2. Smeeth L, Cook C, Hall AJ. Incidence of diagnosed polymyalgia rheumatica and temporal arteritis in the United Kingdom, 1990-2001. Ann Rheum. Dis 2006; 65: 1093-8.

3. Salvarani C, Cantini F, Macchioni P, et al. Distal musculoskeletal manifestations in polymyalgia rheumatica: a prospective followup study. Arthritis Rheum. 1998; 41: 1221-6.

4. Buttgereit F, Dejaco C, Matteson EL, Dasgupta B. Polymyalgia rheumatica and giant cell arteritis: a systematic review. JAMA 2016; 315: 2442-58.

5. Dejaco C, Singh YP, Perel P, et al. 2015 recommendations for the management of polymyalgia rheumatica: A European League Against Rheumatism/American College of Rheumatology collaborative initiative. Ann Rheum Dis. 2015; 74: 1799-807.

6. Salvarani C, Cantini F, Niccoli L, et al. Acutephase reactants and the risk of relapse/recurrence in polymyalgia rheumatica: A prospective followup study. Arthritis Care Res. 2005; 53: 33-8.

7. Dejaco C, Singh YP, Perel P, et al. Current evidence for therapeutic interventions and prognostic factors in polymyalgia rheumatica: a systematic literature review informing the 2015 European League Against Rheumatism/ American College of Rheumatology recommendations for the management of po. Ann Rheum Dis. 2015; 74: 1808-17.

8. Kyle V, Hazleman BL. Treatment of polymyalgia rheumatica and giant cell arteritis. I. Steroid regimens in the first two months. Ann Rheum Dis. 1989; 48: 658-61.

9. Kyle V, Hazleman BL. Treatment of polymyalgia rheumatica and giant cell arteritis. II. Relation between steroid dose and steroid associated side effects. Ann Rheum Dis. 1989; 48: 662-6.

10. Delecoeuillerie G, Joly P, Cohen de Lara A, Paolaggi JB. Polymyalgia rheumatica and temporal arteritis: a retrospective analysis of prognostic features and different corticosteroid regimens (11 year survey of 210 patients). Ann Rheum Dis. 1988; 47: 733-9.

11. Lee JH, Choi ST, Kim JS, et al. Clinical characteristics and prognostic factors for relapse in patients with polymyalgia rheumatica (PMR). Rheumatol Int. 2013; 33: 1475-80.

12. Mackie SL, Hensor EMA, Haugeberg G, et al. Can the prognosis of polymyalgia rheumatica be predicted at disease onset? Results from a 5-year prospective study. Rheumatology (Oxford). 2010; 49: 716-22.

13. Myklebust G, Gran JT. A prospective study of 287 patients with polymyalgia rheumatica and temporal arteritis: clinical and laboratory manifestations at onset of disease and at the time of diagnosis. Br J Rheumatol. 1996; 35: 1161-8.

14. Kremers HM, Reinalda MS, Crowson CS, et al. Relapse in a population based cohort of patients with polymyalgia rheumatica. J Rheumatol. 2005; 32: 65-73.

15. Cimmino MA, Parodi M, Montecucco C, Caporali R. The correct prednisone starting dose in polymyalgia rheumatica is related to body weight but not to disease severity. BMC Musculoskelet Disord. 2011; 12: 94.

16. Jones JG, Hazleman BL. Prognosis and management of polymyalgia rheumatica. Ann Rheum Dis. 1981; 40: 1-5.

17. Healey LA. Long-term follow-up of polymyalgia rheumatica: evidence for synovitis. Semin Arthritis Rheum. 1984; 13: 322-8.

18. Matteson EL, Maradit-Kremers H, Cimmino MA, et al. Patient-reported outcomes in polymyalgia rheumatica. J Rheumatol. 2012; 39: 795-803.

19. Proven A, Gabriel SE, Orces C, et al. Glucocorticoid therapy in giant cell arteritis: Duration and adverse outcomes. Arthritis Care Res (Hoboken). 2003; 49: 703-8.

20. Gabriel SE, Sunku J, Salvarani C, et al. Adverse outcomes of antiinflammatory therapy among patients with polymyalgia rheumatica. Arthritis Rheum. 1997; 39: 1873-8.

21. Goes MC Van Der, Jacobs JWG, Boers M, et al. Patient and rheumatologist perspectives on glucocorticoids: An exercise to improve the implementation of the European League Against Rheumatism (EULAR) recommendations on the management of systemic glucocorticoid therapy in rheumatic diseases. Ann Rheum Dis. 2010; 69: 1015-21.

22. Goes MC van der, Jacobs JWG, Boers M, et al. Monitoring adverse events of low-dose glucocorticoid therapy: EULAR recommendations for clinical trials and daily practice. Ann Rheum Dis. 2010; 69: 1913-9.

23. Dasgupta B, Dolan AL, Panayi GS, Fernandes L. An initially double-blind controlled 96 week trial of depot methylprednisolone against oral prednisolone in the treatment of polymyalgia rheumatica. Rheumatology. 1998; 37: 189-95.

24. Buttgereit F, Doering G, Schaeffler A, et al. Efficacy of modified-release versus standard prednisone to reduce duration of morning stiffness of the joints in rheumatoid arthritis (CAPRA-1): a double-blind, randomised controlled trial. Lancet. 2008; 371: 205-14.

25. Buttgereit F, Mehta D, Kirwan J, et al. Lowdose prednisone chronotherapy for rheumatoid arthritis: a randomised clinical trial (CAPRA-2). Ann Rheum Dis. 2013; 72: 204-10.

26. Cutolo M, Hopp M, Liebscher S, et al. Modified-release prednisone for polymyalgia 
rheumatica: a multicentre, randomised, activecontrolled, double-blind, parallel-group study. RMD Open. 2017; 3: e000426.

27. Veen MJ Van Der, Dinant HJ, Booma-Frankfort C Van, et al. Can methotrexate be used as a steroid sparing agent in the treatment of polymyalgia rheumatica and giant cell arteritis? Ann Rheum Dis. 1996; 55: 218-23.

28. Ferraccioli G, Salaffi F, Vita S De, et al. Methotrexate in polymyalgia rheumatica: preliminary results of an open, randomized study. J Rheumatol. 1996; 23: 624-8.

29. Caporali R, Cimmino MA, Ferraccioli G, et al. Prednisone plus methotrexate for polymyalgia rheumatica: a randomized, double-blind, placebo-controlled trial. Ann Intern Med. 2004; 141: 493-500.

30. Cimmino MA, Salvarani C, Macchioni P, et al. Long-term follow-up of polymyalgia rheumatica patients treated with methotrexate and steroids. Clin Exp Rheumatol. 2008; 26: 395-400.

31. Stone JH. Methotrexate in polymyalgia rheumatica: Kernel of truth or curse of tantalus? Ann Intern Med. 2004; 141: 568-9.

32. Braun J, Kästner P, Flaxenberg P, et al. Comparison of the clinical efficacy and safety of subcutaneous versus oral administration of methotrexate in patients with active rheumatoid arthritis: results of a six-month, multicenter, randomized, double-blind, controlled, phase IV trial. Arthritis Rheum. 2008; 58: 73-81.

33. Diamantopoulos AP, Hetland H, Myklebust G. Leflunomide as a corticosteroid-sparing agent in giant cell arteritis and polymyalgia rheumatica: a case series. Biomed Res Int. 2013; 2013: 1-3.

34. Silva M De, Hazleman BL. Azathioprine in giant cell arteritis/polymyalgia rheumatica: a double-blind study. Ann Rheum Dis. 1986; 45: 136-8.

35. Salvarani C, Macchioni P, Manzini C, et al. Infliximab plus Prednisone or placebo plus prednisone for the initial treatment of polymyalgia rheumatica. Ann Intern Med. 2007; 146: 631-9.

36. Kreiner F, Galbo H. Effect of etanercept in polymyalgia rheumatica: a randomized controlled trial. Arthritis Res Ther. 2010; 12: R176.

37. Macchioni P, Boiardi L, Catanoso M, et al. Tocilizumab for polymyalgia rheumatica: report of two cases and review of the literature. Semin Arthritis Rheum. 2013; 43: 113-8.

38. Mori S, Koga Y. Glucocorticoid-resistant polymyalgia rheumatica: pretreatment characteristics and tocilizumab therapy. Clin Rheumatol. 2016; 35: 1367-75.

39. Régent A, Redeker S, Deroux A, et al. Tocilizumab in giant cell arteritis: a multicenter retrospective study of 34 patients. J Rheumatol. 2016; 43: 1547-52.

40. Stone JH, Tuckwell K, Dimonaco S, et al. Trial of tocilizumab in giant-cell arteritis. N Engl J Med. 2017; 377: 317-28.
41. Devauchelle-Pensec V, Berthelot JM, Cornec $\mathrm{D}$, et al. Efficacy of first-line tocilizumab therapy in early polymyalgia rheumatica: a prospective longitudinal study. Ann Rheum Dis. 2016; 75: 1506-10.

42. Dasgupta B, Cimmino MA, Maradit-Kremers H, et al. 2012 Provisional classification criteria for polymyalgia rheumatica: a european league against rheumatism/american college of rheumatology collaborative initiative. Ann Rheum Dis. 2012; 71: 484-92.

43. Lally L, Forbess L, Hatzis C, Spiera R. Brief report: a prospective open-label phase iia trial of tocilizumab in the treatment of polymyalgia rheumatica. Arthritis Rheumatol. 2016; 68: 2550-4.

44. Matteson EL, Dasgupta B, Schmidt WA, et al. A 2-week single-blind, randomized, 3-arm proof of concept study of the effects of secukinumab (anti-IL17 mAb), canakinumab (anti-IL-1 b mAb), or corticosteroids on initial disease activity scores in patients with PMR, followed by an open-label extension. Arthritis Rheumatol. 2014; 66: S391.

45. Sundahl N, Bridelance J, Libert C, et al. Selective glucocorticoid receptor modulation: New directions with non-steroidal scaffolds. Pharmacol Ther. 2015; 152: 28-41.

46. Hoven JM van den, Tomme SR Van, Metselaar $\mathrm{JM}$, et al. Liposomal drug formulations in the treatment of rheumatoid arthritis. Mol Pharm. 2011; 8: 1002-15.

47. Schwartz DM, Bonelli M, Gadina M, O'Shea JJ. Type I/II cytokines, JAKs, and new strategies for treating autoimmune diseases. Nat Rev Rheumatol. 2016; 12: 25-36.

48. Hartmann B, Liao J, Weisman M, et al. The STAT1 signaling pathway in giant cell arteritis. Arthritis Rheum. 2013; 65: S716.

49. O'Shea JJ, Kontzias A, Yamaoka K, et al. Janus kinase inhibitors in autoimmune diseases. Ann Rheum Dis. 2013; 72: 111-5.

50. Camellino D, Cimmino MA. Imaging of polymyalgia rheumatica: indications on its pathogenesis, diagnosis and prognosis. Rheumatology. 2012; 51: 77-86.

51. Cimmino MA, Camellino D. Large vessel vasculitis: is it more common than usually assumed? Reumatismo. 2017; 69: 143-6.

52. Cantini F, Niccoli L, Storri L, et al. Are polymyalgia rheumatica and giant cell arteritis the same disease? Semin Arthritis Rheum. 2004; 33: 294-301.

53. Cimmino MA, Zampogna G, Parodi M. Is FDG-PET useful in the evaluation of steroidresistant PMR patients? Rheumatology. 2008; 47: 926-7.

54. Dejaco C, Duftner C, Buttgereit F, et al. The spectrum of giant cell arteritis and polymyalgia rheumatica: revisiting the concept of the disease. Rheumatology (Oxford). 2017; 56: 506-15. 